Dipendra Shrestha ${ }^{1}$,

Binod Rajbhandari²,

Sushil Krishna Shilpakar ${ }^{3}$

${ }^{2}$ Senior resident

${ }^{3}$ Professor and Head of Department

Department of Neurosurgery, Tribhuvan University Teaching Hospital, Maharajgunj Medical Campus, Institute of Medicine, Maharajgunj, Kathmandu, Nepal.

\author{
Address for correspondence: \\ Prof Sushil Krishna Shilpakar \\ Department of Neurosurgery, Tribhuvan University \\ Teaching Hospital, Maharajgunj Medical Campus, \\ Institute of Medicine, Maharajgunj, Kathmandu, Nepal. \\ E-mail: sshilpak2001@yahoo.com
}

Date submitted : 9/2/2019

Date accepted : 5/5/2019

\section{Bilobed Thoracic Meningomyelocele: A Case Report With Literature Review}

Neural tube defects (NTDs) arethe most common congenital malformations affecting the brain and spinal cord. Furthermore, meningomyelocele (MMC) is said to be one of the commonest NTDs. Multiple MMC is uncommon and bilobed sac is even rarer, comparatively. In literature, only few such cases have been reported. Here, we present a rare case of bilobed thoracic MMC operated successfully in our department.

Keywords: Multiple neural tube defects, Bilobed thoracic meningomyelocele, Embryogenesis

the swelling was slightly smaller $\left(2.5 \times 3.0 \times 2.5 \mathrm{~cm}^{3}\right)$ compared to the left lobe which was slightly larger (3.0 x $3.0 \times 2.5 \mathrm{~cm}^{3}$ ). Both lobes were covered at the base and isthmus with normal healthy-looking skin; and major part of the two lobes was covered with thinned out see-through skin, resembling an ectopic scrotum externally in the midline of upper thoracic area. (Figure 1) The cough reflex was present on both lobes. Both the lobes and overlying skin was intact; and there was no watery discharge from the lobes. The head circumference was $35 \mathrm{~cm}$; and the anterior fontanel was open and not bulging. The child had normal motor power and sphincter tone. Apart from bilobed swelling, there were no other neurological deficits or observable cutaneous stigmata. MRI of spine revealed bilobed $\mathrm{T}_{1}$ low signal and $\mathrm{T}_{2}$ high signal intensity pouching with septa and connection with the corresponding thecal sac in the upper thoracic level; however there was no overt HCP and Chiari malformation on MRI of brain and craniocervical junction. (Figure 2A and 2B)

The patient underwent excision and repair of MMC under general anesthesia in the prone position. An elliptical incision was made at the base, horizontally incorporating both the lobes of the MMC. (Figure 3) The two sacs were filled with CSF and completely separate from each other and separated by a thick skin band. Circumferential subcutaneous dissection was achieved by meticulously dissecting the two sacs. Tissue in between the two sacs 


\section{Shrestha et al}



Figure 1: Thoracic bilobed meningomyelocele, resembling ectopic scrotum in appearance.
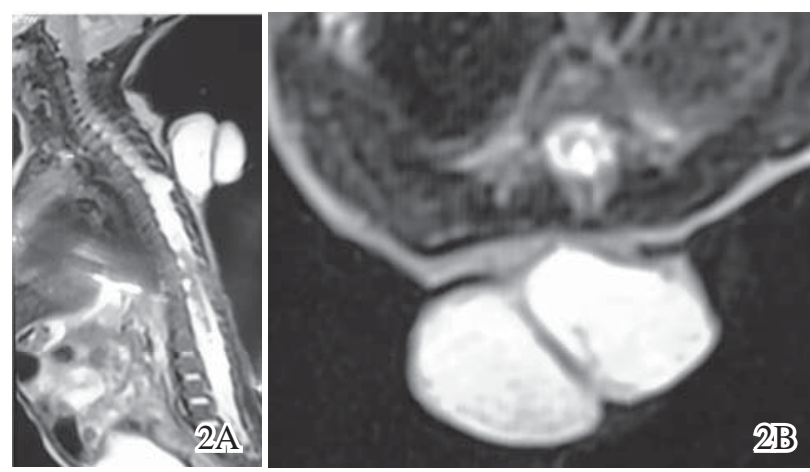

Figure 2: MRI of spine (T2-weighted images) showing a bilobed T2 high signal intensity CSF-filled pouching with septa in an upper thoracic region. Sagittal (2A) and axial (2B) sequencesdepicting the bilobed cyst with septations and in connection with the thecal sac.

was excised; and both sacs were converted into a single sac at the base. The excess skin and sac were excised. The neural elements were dissected and allowed to retract into the thecal sac. Excess dura was excised; and remaining dura was closed in continuous and watertight fashion in two layers via double-sleeving technique. Valsalva maneuver was performed to check for any CSF leak. There was no obvious CSF leak from the dura closure. Finally, the incision was closed in layers; subcutaneous and skin separately using interrupted sutures.

Postoperative course was uneventful. There was no neurological deficit. The child was discharged on third postoperative day. The 4-0 nylon skin sutures were removed after two weeks of surgery during the first follow up visit.

\section{Discussion}

Neural tube defects (NTDs) are common congenital disorders, which occur in approximately 1/1000 births; but the incidence varies among different populations and may be as high as 1/100 births in northern China. ${ }^{11}$ Nutritional and environmental factors have been implicated. The defect may occur anywhere along the vertebral column. Moreover, there have been some reports of multiple NTDs

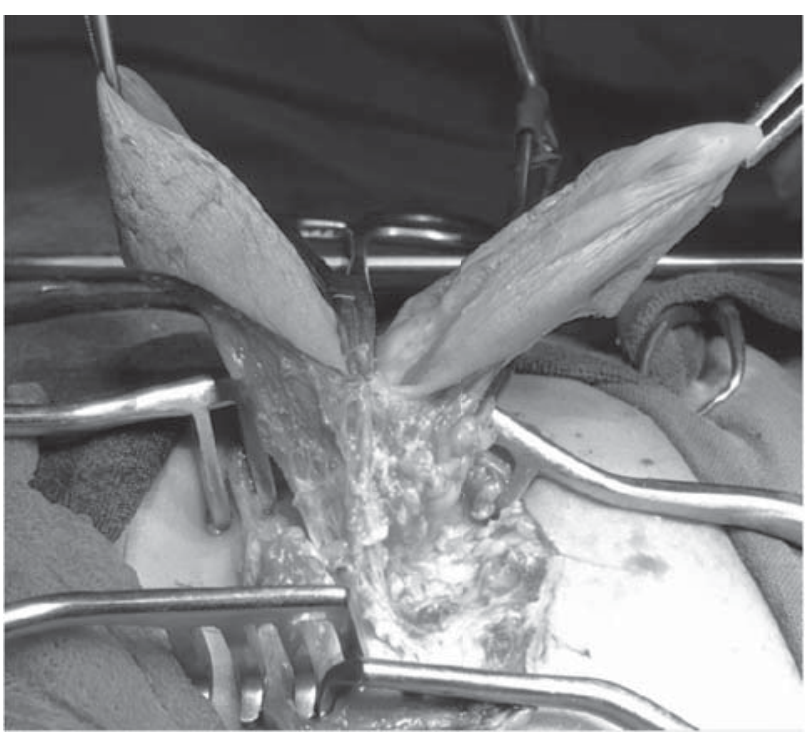

Figure 3: Intraoperative picture showing the bilobed meningomyelocele with two sacs connected in between with normal skin band.

presenting in the same individual ${ }^{1,3-6,8,9,13}$ however, the occurrence of multiple lobes at the same level, so-called bilobed or lobulated MMC is extremely rare. Only a few cases have been reported so far. Goyal et al. ${ }^{6}$ have reported a case of double MMC which was located at back of head, adjacent to each other like double-barrel twin structure. Ahmad el al (2008) ${ }^{2}$ described seven cases of MNTDs which included presence of MMC and/ or encephalocele at multiple (two or more) sites along the vertebral axis. Out of them, case 1 was a full-term one-month-old male child, presenting with two swellings since birth. One was a large, firm lobulated swelling with a central bilobed raw area in the open meningoencephalocele, present in midline parieto-occipital region; and the other was a sessile, midline occipital swelling covered with healthy skin. In 2005, we have reported a case of a three-month-old child, presenting with multiple coexistent dysraphic lesions, including thoracic meningocele and lumbosacral MMC, concurrent Chiari malformation type I, diastematomyelia and lipomyelomeningocele in the lumbosacral region with overt HCP. ${ }^{8}$ Our present case had a bilobed MMC, with septation, resembling an ectopic scrotum in the upper thoracic region, macroscopically.

During embryogenesis in the second week of gestation, ectodermal cells proliferate near the midline of the embryo, forming the neural plate. The neural plate invaginates; and the lateral portions thicken, forming the neural folds at approximately day 17 of gestation. The essential defect is a failure of closure of the caudal neuropore. The resulting lesion involves the spinal cord, a deficient axial skeleton, and an incomplete meningeal and dermal covering. Instead of forming into a tube, the neural folds persist as a flat plate of tissue referred to as neural placode. Spinal 
Thoracic meningocele

defects include a lack of fusion of the vertebral arches, laterally displaced pedicles and a widened spinal canal. ${ }^{10}$ In regards to pathogenesis of spinal dysraphism, the popular widely accepted theory is that neural tube closure is a continuous, bidirectional process which begins in the midcervical region and progresses in a zipper-like fashion both rostrally and caudally, with the cranial and caudal neuropores being the last to close. According to this theory, the most common site of MMC is at the most cranial or most caudal ends; however, this conventional theory fails to explain the multisite or bilobed MMC. Contrarily, in 1993, Van Allen et $\mathrm{al}^{14}$ proposed a multisite neural tube closure model in which five closure sites have been shown to be existing in the neural tube of human embryo. Similarly, Nakatsu et al in $2000^{7}$ found that human neural tube closure initiates at multiple sites in human embryonic study. The multisite neural tube closure model suggests the existence of multiple closure points or "zippers" under the control of one or more genes in normal neural tubes in humans. This finding may explain the occurrence of more than one neural tube defect at different levels. However, it may not be able to fully explain the embryological genesis of bilobed MMC as in our case. In 2010, Goyal et $\mathrm{al}^{6}$ suggested that fusion at cephalic level can be in two separate tracts in a Y-shaped manner, the failure of which may result in a double-barrel defect in suboccipital region. Contrarily, in 2012, Singh et al ${ }^{12}$ did an exhaustive search of the existing theories and concluded that the explanation given by Goyal and colleague was an assumption and had no scientific basis, and that it certainly challenges our existing knowledge of neural tube closure. The same explanation may be assumed for dorsal site bilobed NTD as in our case. In the case reported by Goyal, the MMCs was located in the suboccipital region and was doublebarrel in shape with complete separation in between; whereas in our case, the MMC was located in the upper thoracic region and was bilobed with normal skin into between and not completely separated.

\section{Conclusion}

We have described a rare case of bilobed MMC, occurring in the upper thoracic level with intact overlying skin and without overt HCP or manifestations of Chiari malformation. In regards to embryogenesis, the neural tube gives rise to the brain and the spinal cord to form the central nervous system. Over the past few years various researches has been conducted on brain and spinal cord development in human embryos to discover the embryological basis of complex anomalies. Various theories exist regarding the neural tube closure of multisite or twin neural tube defects. However, none of these theories clearly explain the formation of bilobed neural tube defect.

\section{Reference}

1. Ahmad FU, Agrawal D, Mahapatra AK. Triple meningocele: Cause for a new theory? J Pediatr Neurosci 2:33-34, 2007

2. Ahmad FU, Dwarakanath S, Sharma BS, Mahapatra AK. Multiple neural tube defects: a clinical series of seven cases and their embryological basis. Pediatr Neurosurg 44 (4):280-287, 2008

3. Bailey IC. Double meningocele. Arch Dis Child 46:549-550,1971.

4. Durmaz R, Arslantas A, Ozon YH, Tel E. Double myelomeningocele.Turkish Journal of Pediatrics 42:331-333, 2000

5. Fahrenkrug A, Hojgaard K. Multiple par vertebral lumbar meningocele. Br J Radiol 36:574, 1963

6. Goyal PK, Singh D, Singh H, Tandon M. Suboccipital double barrel twin Meningocele: another new theory? J Pediatr Neurosci 5: 126-128, 2010

7. Nakatsu T, Uwabe C, Shiota K. Neural tube closure in humans initiates at multiple sites: evidence from human embryos and implications for pathogenesis of neural tube defects.AnatEmbryol 201: 455-466, 2000

8. Rai BGK, Shilpakar SK, Bagan M. Multiple dysraphic anomalies with thoracic meningocele and lumbosacral myelomeningocele concurrent with Chiari malformation type I, diastematomyelia, lipomyelomeningocele and hydrocephalus: a case report and literature review. Journal of Institute of Medicine 27 (2):34-38, 2005

9. Rainov NG, Heidecke V, Burkert W. Thoracic and lumbar meningocele in neurofibromatosis type I. Report of two cases and review of the literature. Neurosurg Rev 18:127-34, 1995

10. Sabiston Textbook of Surgery. The biological basis of modern surgical practice.Volume 2, $17^{\text {th }}$ edition. Elseviers; pp. 2171-2172

11. Sadler TW. Langman's Medical Embryology. $11^{\text {th }}$ ed. Wolter Kluwer;pp. 302, 2010

12. Singh DK, Singh N, Kumar P. Double suboccipital meningoencephalocele: a unique case report. Pediatr Neurosurg 48:331-332, 2012

13. Tekkok IH. Triple neural tube defect-cranium bifidum with rostral and caudal spina bifida-live evidence of multi-site closure of the neural tube in humans. Childs Nerv Syst 21:331-335, 2005

14. Van Allen MI, Kalousek DK, Chernoff GF, et al. Evidence for multisite closure of the neural tube in humans. Am J Med Genet 47: 723-743, 1993 